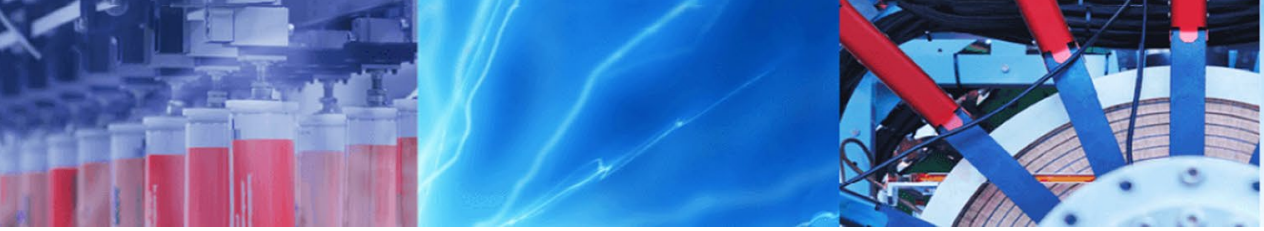

Case Study

\title{
A case study on the observability of cutting fluid flow and the associated contact mechanics in scaled rough surfaces
}

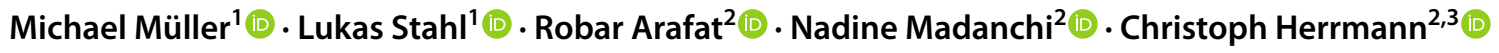

Received: 23 October 2020 / Accepted: 10 April 2021

Published online: 20 April 2021

C The Author(s) 2021 OPEN

\begin{abstract}
In grinding processes, heat is generated by the contact of the grains with the workpiece. In order to reduce damages on the workpiece and the grinding tool, cutting fluids are necessary for most grinding processes. They have the tasks of cooling and lubricating the contact zone and to remove the chips from the contact area. Different types of cutting fluids perform differently regarding these tasks, which can be investigated on a laboratory scale. However, the results of those experiments are limited to certain workpieces and processes and information about the contact mechanics are not available. The experimental investigation of contact mechanics under cutting fluid influence is hardly possible. For this reason, this paper uses a measurement strategy that uses scaled topographies and has already been successfully applied to contact mechanics problems. With such a setup, it is intended that at an early stage in the development of cutting fluids, their characteristics in terms of contact mechanics can be determined very efficiently. To demonstrate this approach, two different cutting fluids were tested with the help of the associated test rig-a water miscible emulsion and a non-water miscible grinding oil. The two fluids showed fundamentally different characteristics regarding their hydrodynamic load bearing effect, their influence on the friction behavior of the contact and their fluid flow in the gap. The properties analyzed here correspond to the practical application of cutting fluids. The results underline the potential of the presented setup for an integration into the development process of cutting fluids.
\end{abstract}

Keywords Grinding · Cutting fluid · Contact mechanics · Experiments · Fluid flow · Hydrodynamics

\section{Introduction}

Grinding processes offer the possibility to achieve high surface qualities and dimensional accuracy. As grinding is a finishing step at the end of the process chain, optimized and faultless grinding processes are highly relevant regarding their technological, economic and also ecological performance. In addition, grinding technology is being expanded through the development of new abrasive materials and technologies, enabling it to compete with other manufacturing processes [1]. For grinding applications, investigations are usually carried out using complex empirical approaches.

The contact of the grains with the workpiece leads to frictional heat. The generated heat is distributed to the workpiece, tool, the environment and the cutting fluid. Because of the large contact lengths along the grinding wheel, the contact zone temperature in grinding processes is high compared to other cutting processes. Therefore, in most grinding processes, the use of cutting fluids is

$\triangle$ Michael Müller, mi.mueller@tu-bs.de | Institute of Dynamics and Vibrations, Technische Universität Braunschweig, Schleinitzstr. 20, 38106 Braunschweig, Germany. ${ }^{2}$ Institute of Machine Tools and Production Technology, Sustainable Manufacturing and Life Cycle Engineering Research Group, Technische Universität Braunschweig, Langer Kamp 19b, 38106 Braunschweig, Germany. ${ }^{3}$ Fraunhofer Institute of Surface Engineering and Thin Films (IST), Bienroder Weg 54 E, 38106 Braunschweig, Germany. 
essential. The aim of an effective cooling is hereby to increase the heat proportion of the cutting fluid to reduce thermal damage on tool and workpiece. The main tasks of the cutting fluids are to cool and to lubricate the cutting zone. Another important task of cutting fluids is the removal of chips and the cleaning of the process zone. Secondary tasks are corrosion protection and machine tempering [1]. According to DIN 51385 [2], there are two categories of cutting fluids, water-miscible and non-watermiscible cutting fluids. Water-miscible cutting fluids are emulsions and solutions, which mostly consist of approximately $95 \%$ water and base concentrate. They are characterized by good cooling properties because of the high water content. Non-water-miscible cutting fluids, on the other hand, are usually mineral oil based and have a higher viscosity. These cutting fluids have a better lubricating effect and therefore show better results for many grinding processes than water-miscible cutting fluids [1, 3].

A pre-selection of suitable cutting fluids for a specific grinding process is already being made in laboratories. Numerous different test equipments and methods are available for investigating the friction and wear behavior of the lubricant. For the investigation of cutting fluid formulations and their influence on the tribological behavior, the use of the Brugger and Reichert test are established in practice. These methods can be used to determine the pressure absorption capacity of the cutting fluid. An example of the scientific use of the Reichert friction wear test is the investigation of nanofluids [4]. The Brugger test was, for example, used to investigate novel types of microorganism-based cutting fluids [5]. However, the use of the tests is limited to certain materials, workpiece geometries and the transferability to the real use case is limited. In particular, these test methods do not use grinding wheels with actual cutting edges and also the parameters such as rotational speed differ significantly from real grinding processes.

One possibility to characterize the chip formation is single grit grinding. In this test, the grinding process is represented by the contact of a single grain and various parameters such as the forces [6] or the surface structure [7] are analyzed. For thread forming and cutting, tapping torque test benches are used to characterize cutting fluid properties. Thread cutting tests were for example carried out on a laboratory tapping device in [8]. Thread forming and cutting tests use standardized threading parameters to evaluate the cutting fluid as the only variable in a process. Therefore, these test methods are mainly designed for threading. The results about the cutting fluids are therefore mainly applicable on threading processes, which limits the use of the test methods.

Because of the high discrepancy of the experiments on laboratory level to the processes on industrial level, cutting fluids are furthermore investigated on industrial machine tools. In particular, the influence of the cutting fluid supply cannot be sufficiently investigated at laboratory level. For example, the air layer around the grinding wheel that restricts the cutting fluid to reach the grinding wheel efficiently is investigated on machine level. The negative effects of the air layer increase with the grinding wheel speed [9]. Another research field is the effective cutting fluid flow passing the contact area. Based on the experimental investigations, the smallest possible horizontal nozzle distance to the grinding wheel $[10,11]$ a tangential angle of the nozzle [9] an adapted nozzle geometry including an adapted cutting fluid velocity [12] and a high grinding wheel porosity have a positive effect on the contact zone volume flow. In addition, experimental pressure measurements were carried out in the grinding gap, which showed a maximum cutting fluid directly in front of the grinding gap [13]. The mentioned test methods are used to characterize cutting fluids. However, information about the contact mechanics and the fluid behavior in the contact are not provided. In terms of contact mechanics, grinding is a process that is in the regime of boundary friction to mixed friction.

Figure 1 schematically illustrates the complex interactions in the contact zone during the grinding process. The upper part of the figure shows the most relevant system parameters for grinding which determine the physical processes (framed in the lower figure). These are essentially influenced by the cutting fluid (see corresponding arrows) as discussed in the following. The cutting fluid determines the depth of penetration of the abrasive grains into the

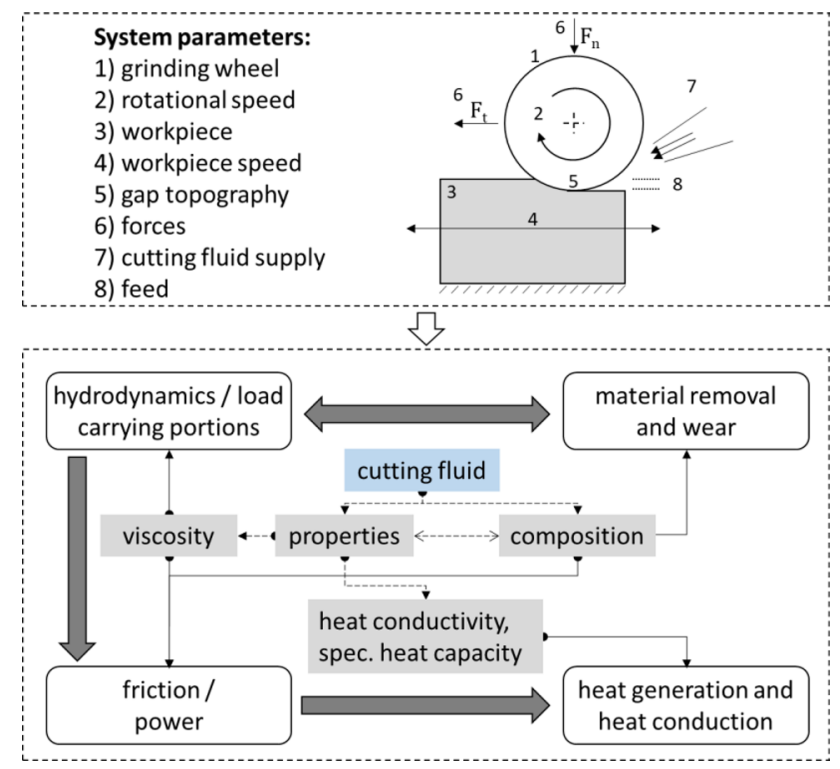

Fig. 1 Scheme of the interactions in the contact zone of grinding processes under presence of cutting fluids 
workpiece, particularly with its viscosity property. Higher viscous fluids generate a corresponding load carrying capacity due to the hydrodynamic pressure buildup, which reduces the penetration depth of the grains. This also results in a significant influence on the frictional power, which is made up of the two components "solid contact through grain/workpiece" and "shearing of the fluid". Both components are strongly influenced by the cutting fluid composition. The energy dissipated by the frictional power heats the workpiece and the grinding wheel as well as the fluid, whereby the distribution is determined by the thermal conductivities, specific heat capacities and the heat transfer coefficients. Beyond that, the penetration depth also determines the material removal rate (additives also play a major role here) as well as the elastic deformations, which, in turn, influence the gap topography and thus the load distribution. This very strong and nonlinear interaction of the mechanical and thermal processes is a main reason for a lack of understanding of the contact mechanical influence of the selected cutting fluids.

With respect to contact mechanics, grinding is a tribological process in which two rough surfaces slide against each other under the influence of a cutting fluid, whereby one of the surfaces (the grinding wheel) is usually much rougher. Depending on the lubrication strategy and the type of supply, scenarios can also occur in which the gap is not completely filled by the fluid. There are numerous publications on the investigation of the interactions of lubricated rough surfaces, e.g. based on molecular dynamics [14] (which is effective for ultra-thin films with nanometer thickness), on Lattice-Boltzmann methods (for complex flows through very rough surfaces) or based on the complete Navier-Stokes equations [15]. In [16, 17] the Reynolds equation has been used for describing gap flows in grinding processes. Contact mechanical models have also been developed for gaps that are only partially filled, i.e. for starved lubrication. This work also is the basis for the test rig presented below, which is used to validate the model presented in [18], including the formation of certain flow patterns [19] and incorporating solid-solidcontacts [20].

In order to describe the contact mechanical processes on a scale where the surface roughness is crucial, a basic understanding of the fluid flow through the contact zone as well as the resulting gap height is essential. In grinding applications, where roughness is usually in the lower micrometer range, this objective poses considerable problems with respect to observability. Consequently, experimental studies on this problem are not yet available in the literature.

Regardless of this problem, in the research field of fluid mechanics, it is common practice to scale systems. Here it is important to ensure that characteristic numbers, such as the Reynolds number, match between the real and scaled system. The application of a scaling of tribological systems, accompanied by a transfer of the information from, for example, a millimeter scale to a micrometer scale, is to be seen quantitatively quite critically but nevertheless, for phenomenological purposes a first practical approach to these questions.

Against this background, a concept was presented in [21] with which such investigations could be carried out. For this purpose, a new type of test rig was used, in which two rough ornamental glass panes were moved against each other and the occurring forces and torque were recorded. In addition, the movement of the fluid is recorded by a camera so that the video material can be potentially used to detect unsteady and stationary flow characteristics. This test rig is also used for this paper and is described further in chapter 2 . Since this paper is based on these recent studies, the main results from [21] are summarized briefly below.

The measurements in [21] show that the Stribeck curve can be traced over a varying speed. A similar effect can be seen if the amount of fluid initially introduced into the contact is varied. Small amounts of fluid correlate with boundary and mixed friction; an increase in the amount of fluid leads to a shift towards hydrodynamics. In correlation to the video recordings, it could be clearly determined how the hydrodynamic influence correlates with the flow pattern [21]. In partially filled systems, it was evident that a high degree of hydrodynamic power transmission was coupled with a "ring formation" of the fluid that is associated with continuous fluid transport, whereas a state with a significantly lower hydrodynamic load-carrying capacity tended to form "islands" that are associated with fluid displacement.

Until now, these tests have been carried out exclusively on test fluids, i.e. pure glycerol and glycerolwater-mixtures. Experimental studies on the influence of cutting fluids on the interactions in rough contacts are not available yet but essential for a better understanding of their functioning. Consequently, it will be investigated whether the mechanisms identified so far with the Wear Debris Investigator (WDI, see chapter 2) and their dependence on viscosity, relative speed and fluid quantity can be determined for cutting fluids. These findings can contribute significantly to the understanding of effects and phenomena in the boundary layer of a grinding system. For this purpose, in this paper, the aim is to demonstrate the feasibility of this measurement strategy to characterize industrial cutting fluids in grinding processes. With this approach, a base for further studies regarding the interactions of contact mechanics and cutting fluids is created. 


\section{Experimental setup}

The following description of the test rig and the test procedure are strongly based on the experiments described in the previous section. For further details regarding the experimental setup please also see [21-23].

\subsection{Test rig}

Figure 2a shows the WDI test rig concept developed and used by Ostermeyer [22] and further developed [23] for the observation of particle dynamics in dry friction contacts. Figure $2 \mathrm{~b}$ ) illustrates the structure of the actual contact area. Here, particles or fluids can be initially introduced between two glass disks. The normal force is applied via the upper contact area in the form of dead weight or a variable preload via a lever. The lower surface is rotated by a motor via a toothed belt. The normal force and the torsional moment are measured just above the contact with the Kistler 2-component sensor 9365B, while information about a gap height change in operation is collected by the laser sensor Micro-Epsilon optoNCDT 2300-200. The particle or fluid movement is observed by a camera, which records the bottom view of the images via a mirror.

In addition to the use of this test rig for dry systems with particles, studies with fluids and ornamental glass panes were also carried out within the framework of a research project on basic investigations of tribological contacts [21]. The glass panes are also used in this study and are shown in Fig. 3a. Figure 3b shows a section of the measured surface topography of this glass pane. The mean roughness of these "scaled" surfaces is $0.222 \mathrm{~mm}$. All measurements shown in this study were accomplished with the same two glass panes.

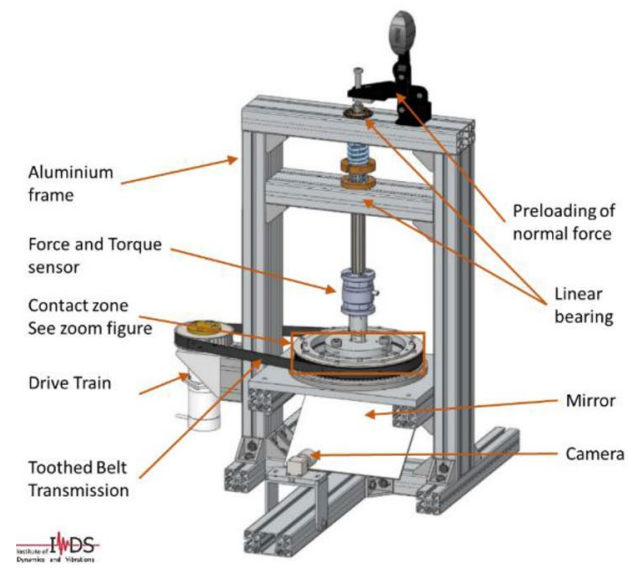

(a)

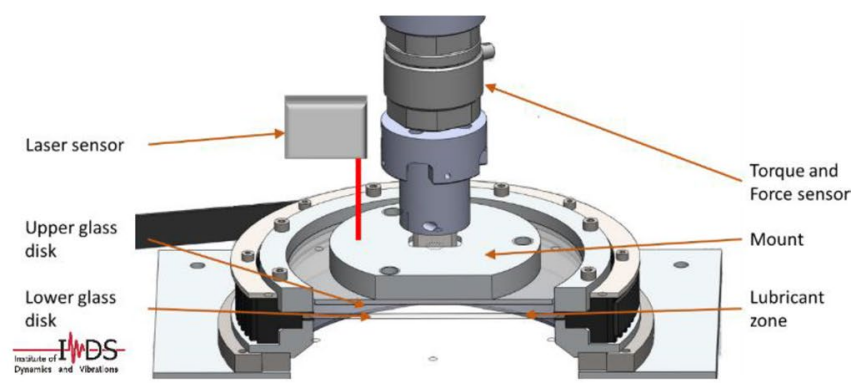

(b)

Fig. 2 WDI test rig: a overview, b detail of the contact section [22]

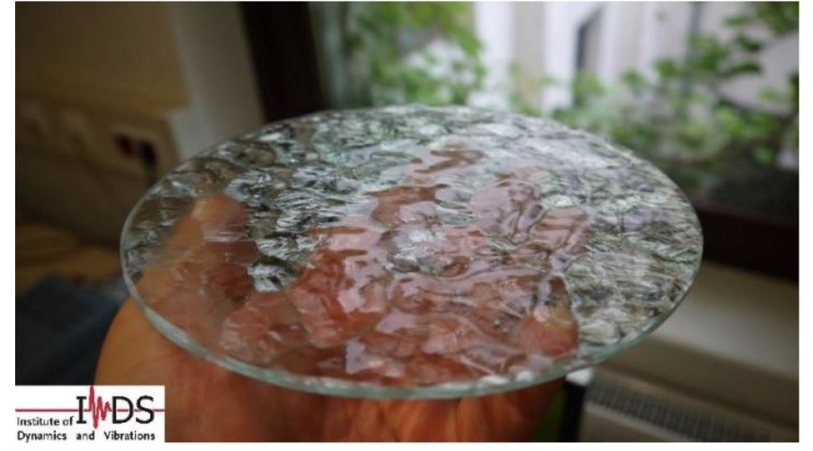

(a)

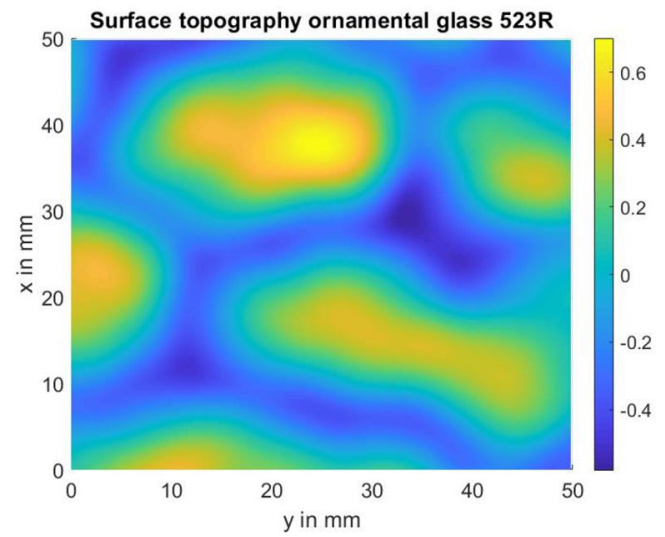

(b)

Fig. 3 a Glass panes used (ornament 523 R), b Section of the measured surface topography [21] 
Table 1 Densities and viscosities of the tested cutting fluids at $20^{\circ} \mathrm{C}$

\begin{tabular}{lll}
\hline & $\begin{array}{l}\text { Aerolan } 2410 \\
\text { emulsion }\end{array}$ & $\begin{array}{l}\text { SCO } 310 \\
\text { grinding } \\
\text { oil }\end{array}$ \\
\hline Density $\left(\mathrm{g} / \mathrm{cm}^{3}\right)$ & 0.99 & 0.89 \\
Kinematic viscosity $\left(\mathrm{mm}^{2} / \mathrm{s}\right)$ & 1.45 & 29 \\
Dynamic viscosity $(\mathrm{mPa} \cdot \mathrm{s})$ & 1.44 & 25.8 \\
\hline
\end{tabular}

\subsection{Cutting fluids and test procedure}

The experiments were carried out using Aerolan 2410 (manufacturer: DAW Aerocit Schmierungstechnik GmbH) as a water-based cutting fluid (emulsion with $90 \%$ water content). In contrast, SCO 310 (manufacturer: Carl Bechem $\mathrm{GmbH}$ ) as a non-water-miscible grinding oil was tested. The characteristic values of density and viscosity at $20^{\circ} \mathrm{C}$ are given in Table 1. The normal load is applied by the upper part's dead weight, which amounts $30 \mathrm{~N}$.

The measurement procedure includes the variation of two parameters: relative velocity and global filling level. The relative velocity was controlled via the rotational speed of the disk. The filling level was modified by the initially applied amount of cutting fluid in the gap. The fluid volume was manually applied onto the contact using a high precision syringe. To apply the fluid, the upper disk was raised. No leakage was detected during the test, so it was assumed that the fluid volume was constant. During a measurement procedure, first, a variation of the rotational speed was carried out, after which the smallest amount of fluid was added. Next, the speed was varied for every new amount of fluid. After the measurement set with the greatest amount of fluid (fully filled state), the WDI was disassembled and cleaned. Then, the entire procedure was repeated a minimum three times for statistical purposes. In addition, one test series with distilled water was carried out for a comparison with the emulsion.

The gap was initially filled with different amounts of fluid (from $2.25 \mathrm{ml}$, which corresponds to a filling level of $15 \%$, to $15 \mathrm{ml}$, which corresponds to a filling level of $100 \%$ (full filling)). The rotational speed was varied from 6 to $60 \mathrm{rpm}$ (current maximum possible rotational speed, which corresponds to a maximum speed at the outer edge of approx. $0.5 \mathrm{~m} / \mathrm{s}$ ). The complete test matrix is summarized in Table 2.

The duration of each individual measurement was always $10 \mathrm{~s}$, with slight differences in the time evaluated so that only full revolutions were considered (e.g. at $6 \mathrm{rpm}$ $10 \mathrm{~s}$ is 1 revolution, at $25 \mathrm{rpm} 9.6 \mathrm{~s}$ is 4 full revolutions and so on). Due to the short duration and the high roughness wear does not play a significant role in these experiments. This aspect has been proven in [21]. The measured data
Table 2 Test matrix with varying rotational speeds and fluid quantities

\begin{tabular}{lllll}
\hline & \multicolumn{4}{l}{ Amount of fluid in ml (filling level percentage) } \\
\cline { 2 - 5 } & $2.25(15 \%)$ & $4.5(30 \%)$ & $9.0(60 \%)$ & $15.0(100 \%)$ \\
\hline $\begin{array}{l}\text { Rotational } \\
\text { speed in } \\
\text { rpm }\end{array}$ & & & & \\
6 & 0 & 0 & 0 & 0 \\
25 & 0 & 0 & 0 & 0 \\
40 & 0 & 0 & 0 & 0 \\
60 & 0 & 0 & 0 & 0 \\
\hline
\end{tabular}

was used to calculate a time-averaged torque and normal force. An average friction coefficient was thus calculated over the effective radius (corresponds to $2 / 3$ of the disc radius, for details, see also [21]).

\section{Results and discussion}

For fully-flooded conditions, the friction coefficient over the rotational speed under presence of the emulsion is plotted in Fig. 4a. For all measurements "rpm" refers to the rotational velocity of the lower glass pane in revolutions per minute. 3 repetitions of a measurement with the same parameters are shown ("Series 1", "Series 2" and "Series 3"). For comparison, this diagram also shows the corresponding curve for distilled water ("COF Water"). The measured quantities clearly indicate that the systems run in the range of dry friction. The repeatability of the experiments, especially up to $40 \mathrm{rpm}$, is very good. The increasing trend of the friction coefficient with increasing rotational speed probably does not indicate a Stribeck-like behavior here, but rather a special dynamic, which is assumed to be determined by the solid-solid-contacts. Figure $4 \mathrm{~b}$ shows the trend of the coefficient of friction over the quantity of emulsion supplied at $40 \mathrm{rpm}$ and as the reference the trend of distilled water. It illustrates that here dry friction practically occurs independently of the quantity of the cutting fluid supplied. With increasing quantity, the coefficient of friction changes only relatively little; these measurement results are also very well reproducible. What is also remarkable is the similarity between the emulsion and pure water. In terms of mechanical interactions, the emulsion thus plays only a subordinate role under the load conditions examined here.

From the measured values of the emulsion, it can therefore be assumed that hydrodynamics hardly occur in this configuration. This would require higher speeds or lower forces (which was not easily possible with the existing test rig). 


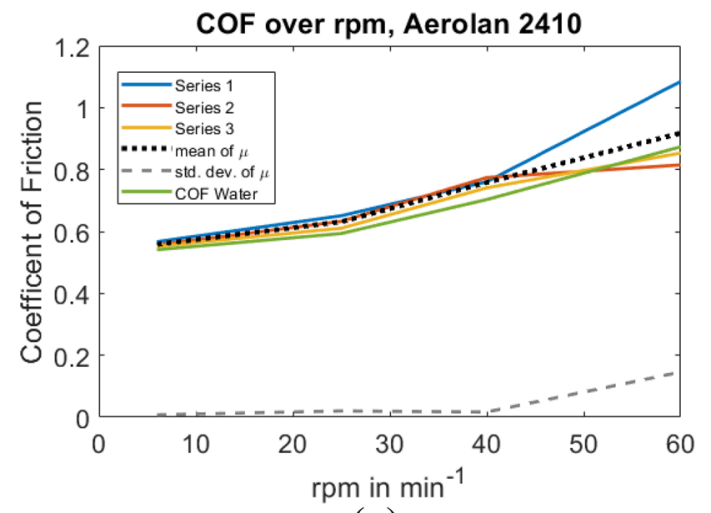

(a)

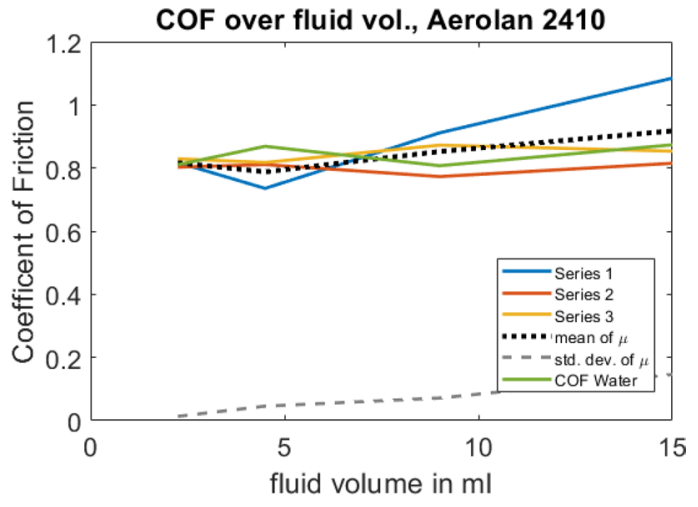

(b)

Fig. 4 Measured friction coefficient for an Aerolan 2410 ( $10 \%$ emulsion): a over rotational speed at full filling, b over fluid volume at $40 \mathrm{rpm}$

Figure 5 a shows the corresponding trend of the coefficient of friction over the rotational speed with a fully filled gap for the grinding oil. Here, the experiments also show a good repeatability. The measured coefficient of friction with a value of about 0.13 is clearly below the value of the emulsion, which is obviously due to the viscosity, which is higher by a factor of 18 . In this system, this value characterizes very reliably a strongly hydrodynamic load bearing behavior. The fact that the friction coefficient is almost independent of speed is probably also due to the load range, especially the low relative speed ( $\max .0 .5 \mathrm{~m} / \mathrm{s}$, see above). The influence of different additives on these results were not investigated, but it can be assumed that they are partly responsible for this behavior and should be further investigated.

A very interesting behavior can be seen in the variation of the total fluid quantity (see Fig. 5b). Whereas with emulsion, regardless of the quantity, solid body friction practically always occurs (correlated with the high COFs, see Fig. 4b) with grinding oil there is practically always hydrodynamic or a strong additive influence (correlated with the high COFs, see Fig. 5b). This means that even very small quantities of grinding oil are sufficient to change the load-carrying behavior from solid-solid-contact to lubricated contact.

The previous statements are supported by the laser distance measurements. In Fig. 6, the time-averaged changes of the gap height over the varying speeds are plotted for the fully filled state. Since information on the absolute height is technically difficult to obtain due to the test design, relative statements are made here, whereby the value at the lowest speed ( $6 \mathrm{rpm})$ serves as the reference (i.e. at $6 \mathrm{rpm}$ the gap height increase $\mathrm{GHI}=0$ ).

While using emulsion, an increase in the mean gap height of partially over $100 \mu \mathrm{m}$ and on average $70 \mu \mathrm{m}$ at $60 \mathrm{rpm}$ can be clearly observed with increasing speed (see Fig. 6a), this value for the grinding oil (see Fig. 6b) is a maximum of $4 \mu \mathrm{m}$, on average around $0 \mu \mathrm{m}$ ). The latter values have the same order of magnitude as the resolution of the laser sensor, so that it can be concluded that, especially in relation to the roughness of the glass panes $(222 \mu \mathrm{m})$, no significant change in gap height can

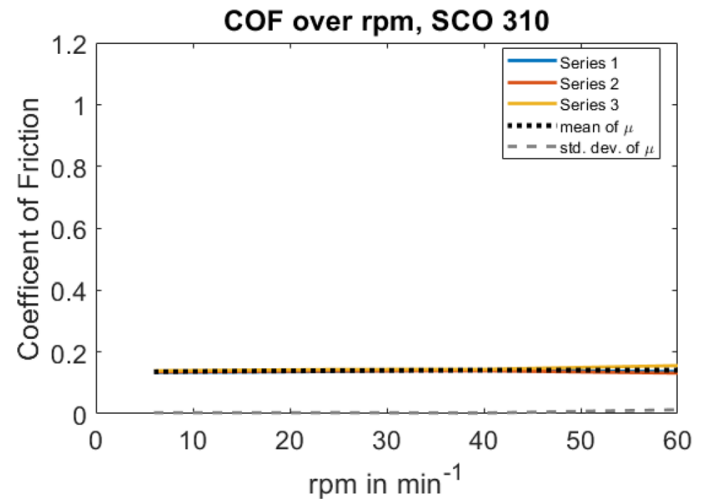

(a)

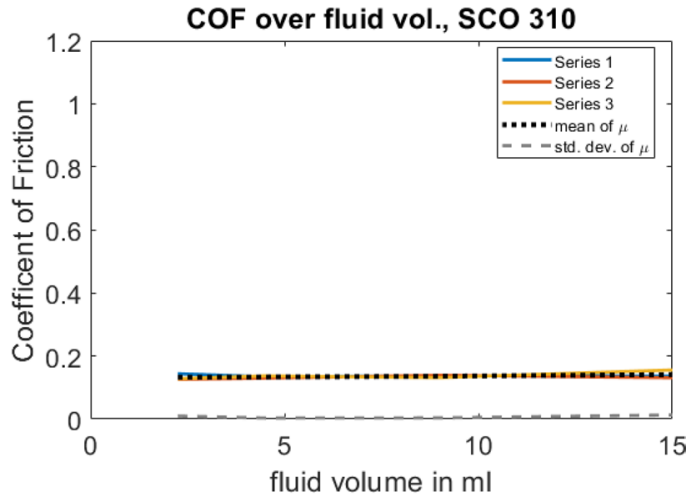

(b)

Fig. 5 Measured coefficient of friction for grinding oil: a over rotational speed when fully filled, $\mathbf{b}$ over the fluid quantity at $40 \mathrm{rpm}$ 


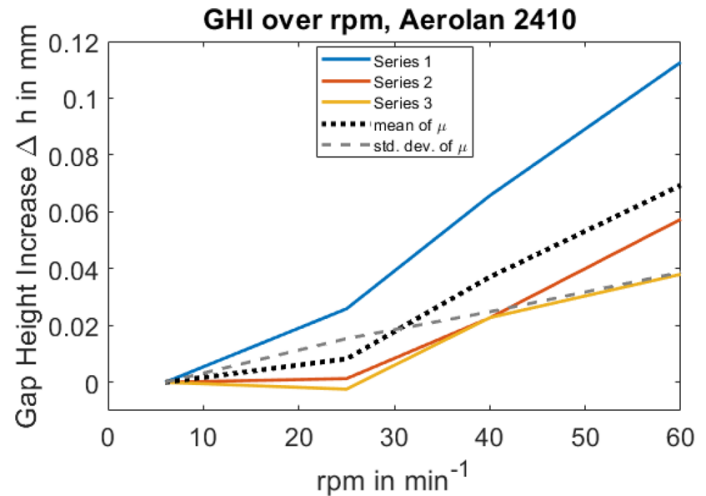

(a)

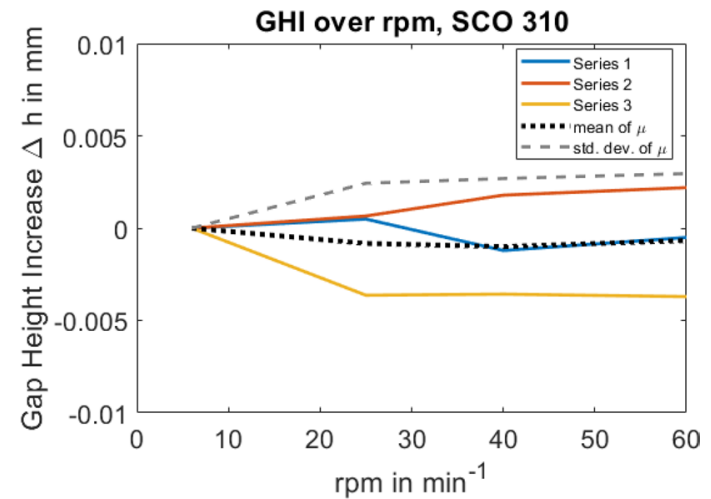

(b)

Fig. 6 Measured gap height increase over rotational speed when fully filled: a Aerolan 2410 emulsion with $90 \% \mathrm{H}_{2} \mathrm{O}$, b grinding oil

be detected using the grinding oil. The only change in the values is due to measurement noise. This is also confirmed by the trends shown in Fig. 5b, in which the frictional state remains unchanged hydrodynamically, practically independent of the amount of fluid and speed of rotation, which correlates with low contact forces.

The significant increase of the gap height with increasing speed when using the emulsion indicates high dynamic condition with high contact forces (as also documented in Fig. 5a), which results in a corresponding lifting of the upper glass pane. Although this property is on the one hand something specific to the measuring system, it also reflects the fact that a gap widening can be expected due to such dynamics in dry systems.

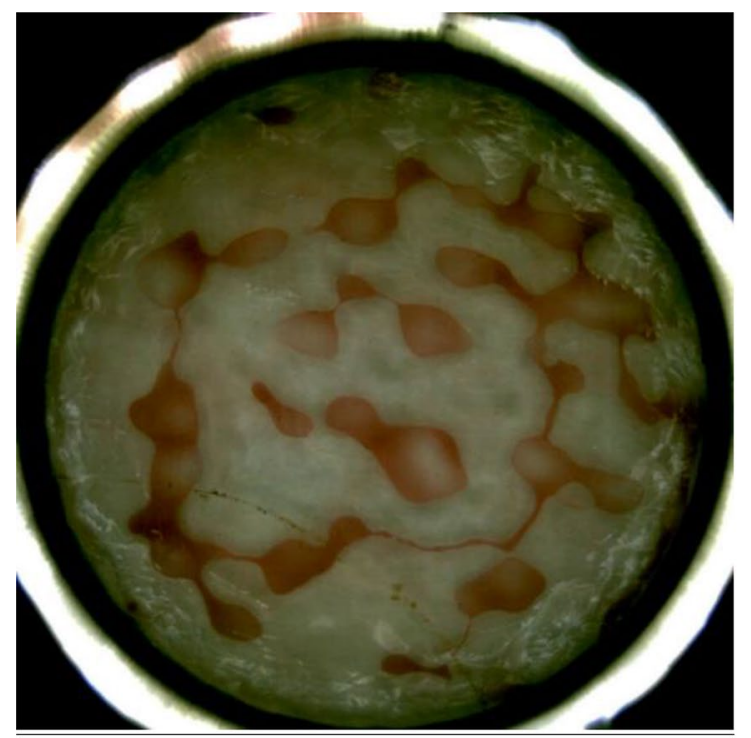

(a)
Figure 7 shows freeze images from the respective videos, which can be regarded as representative of the flow. To show the flow characteristics more clearly, a partially filled gap with $30 \%$ filling degree at a rotational speed of $40 \mathrm{rpm}$ is shown here. In order to achieve a better contrast, the emulsion (Fig. 7a) was dyed red with food coloring, the grinding oil (Fig. 7b) could not be dyed appropriately.

These pictures confirm the findings of the preliminary work on basic tribological investigations [21], i.e. that the fluid flow and the pattern of the flow depends on the friction state (hydrodynamics or solid-solid-contact). The fluid, which does not produce a significant hydrodynamic load-bearing effect (the emulsion), rather forms islands (see Fig. 7a), which do not represent a continuous fluid transport. Rather, the fluid is displaced when asperities

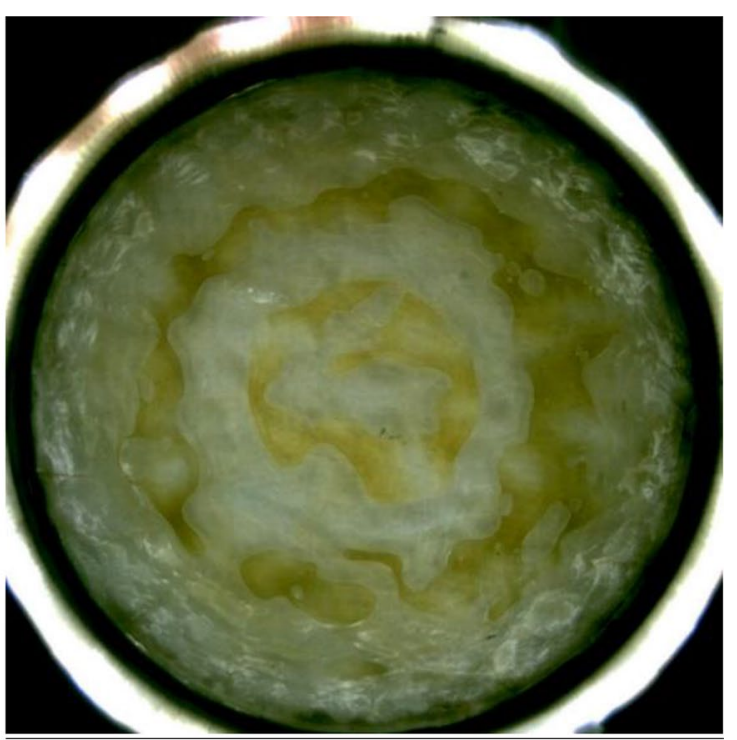

(b)

Fig. 7 Freeze image for the flow at $40 \mathrm{rpm}$ and a filling level of $30 \%$ : a of the emulsion with $90 \% \mathrm{H}_{2} \mathrm{O}$ content (colored), b grinding oil 
approach, but then runs back into the valley (the island). A different behavior is shown with the grinding oil (Fig. 7b). Due to the hydrodynamic supporting effect, ring-like fluid distributions are formed, which are associated with a continuous fluid flow. This impression from the still images can be seen even more clearly in the videos.

\section{Conclusion and outlook}

Cutting fluids are necessary in grinding processes to reduce damage to workpiece and tool as well as to ensure dimensional accuracy. Their main tasks are to cool and to lubricate the contact zone and to remove the chips from it. To characterize cutting fluids, experiments are carried out both on laboratory and machine tool level, which creates a good empirical understanding of mechanical and thermal relationships of grinding processes. However, there is still no basic understanding of the influence of the cutting fluid in the contact zone during grinding. This is mainly due to the complexity of the associated contact mechanics. An experimental approach to this question does not exist up to now, because the observability of fluid flow through microscopic roughness is hardly possible. For this reason, a strategy has been applied here that was previously successfully applied in basic tribological investigations. In the previous study, scaled topographies on a millimeter scale were investigated under the influence of academic fluids (pure glycerol and glycerol-water-mixtures). Within the presented research approach, this strategy was applied to industrial cutting fluids to investigate the transferability to these fluids and to help with the understanding of the phenomena occurring in the contact.

For this purpose, both a rather low-viscosity waterbased cutting fluid in the form of an emulsion and a higher-viscosity oil-based cutting fluid were used. With regard to the lubricating effect, the main question is how large the hydrodynamic contact ratio is, which reduces the effective force for machining and how the interaction with fluid transport can be described. With the test rig, first qualitative findings about how the system-determining quantities and processes, such as the friction coefficient, the hydrodynamic load-bearing effect, the gap height, the fluid quantity and how the fluid transport interact with each other could be obtained. The influence of the cutting fluid on friction and fluid transport is clearly visible here. With the help of the test rig it has been clearly shown that over a wide speed range and a wide variation of the supplied fluid quantity, the grinding oil led to a hydrodynamic friction regime, whereas with the emulsion, solid-solidcontact was always present.

The close connection between fluid transport and hydrodynamic load-bearing effect is one of the central questions with regard to the design of grinding processes, since this determines in particular the efficiency of the grinding process and the heat transport. Basic investigations on this scale can therefore be very helpful in a phenomenological sense to gain a better understanding of the underlying process dynamics. Against this background, this case study was a first step that should form the basis for future detailed studies. The fact that a very good distinction was possible with regard to the characteristics of two completely different types of cutting fluids, and that this corresponded to experience from the application, indicates the great potential of this experiment. Such a test rig thus offers a possibility to be integrated into the development process of cutting fluids in order to be able to deduce required contact mechanical properties at a very early stage with relatively little effort.

In order to achieve the real load and parameter range of grinding, the test rig will be extended in particular to allow for higher rotational speeds. In addition, it is also conceivable that in the future a fine abrasive paper could be attached to the upper side of the contact in order to get closer to the real grinding contact topographically. Furthermore, it is planned to add tracer particles to the cutting fluid in order to evaluate the flow properties more specifically. The influence of individual additives on fluid behavior can also be investigated. In addition, the authors intend to compare the findings obtained in this way with the results of grinding experiments on industrial machines by relating the characteristics of the forces (normal and tangential) and the resulting surface topographies (which are correlated with the penetration depth of the grain). This research path will be accompanied by appropriate simulations to support and validate the results.

Funding Open Access funding enabled and organized by Projekt DEAL.

Availability of data and material Upon request, the raw data of the measurements could be provided.

Code availability Not applicable.

Declarations

Conflicts of interest The authors declare that they have no conflict of interest.

Open Access This article is licensed under a Creative Commons Attribution 4.0 International License, which permits use, sharing, adaptation, distribution and reproduction in any medium or format, as long as you give appropriate credit to the original author(s) and the source, provide a link to the Creative Commons licence, and indicate if changes were made. The images or other third party material in this article are included in the article's Creative Commons licence, unless indicated otherwise in a credit line to the material. If material is not 
included in the article's Creative Commons licence and your intended use is not permitted by statutory regulation or exceeds the permitted use, you will need to obtain permission directly from the copyright holder. To view a copy of this licence, visit http://creativecommons. org/licenses/by/4.0/.

\section{References}

1. Klocke $F$ (2009) Manufacturing processes 2: grinding, honing, lapping. Berlin, Heidelberg: Springer [Online]. Available: http:// search.ebscohost.com/login.aspx?direct=true\&scope=site\&db= nlebk\&db=nlabk\&AN=277215

2. DIN 51385 (2013) Schmierstoffe - Bearbeitungsmedien für die Umformung und Zerspanung von Werkstoffen - Begriffe

3. Brinksmeier E, Meyer D, Huesmann-Cordes A-G, Herrmann C (2015) Metalworking fluids-mechanisms and performance. CIRP Ann Manuf Technol 64(2015):605-628. https://doi.org/10. 1016/j.cirp.2015.05.003

4. Madanchi N, Zellmer S, Winter M, Flach F, Garnweitner G, Herrmann C (2019) Investigation on the effects of nanoparticles on cutting fluid properties and tribological characteristics. Int J Precis Eng Manuf Green Technol 6(3):433-447. https://doi.org/ 10.1007/s40684-019-00053-0

5. Seidel B, Rabenstein A, Redetzky M, Wagner A, Brinksmeier E (2017) Performance evaluation of metalworking fluids based on microorganisms. Prod Eng Res Devel 11(1):41-49. https:// doi.org/10.1007/s11740-016-0711-6

6. Matsuo T, Toyoura S, Oshima E, Ohbuchi Y (1989) Effect of grain shape on cutting force in superabrasive single-grit tests. CIRP Ann 38(1):323-326. https://doi.org/10.1016/S0007-8506(07) 62714-0

7. Öpöz TT, Chen X (2014) Experimental study on single grit grinding of Inconel 718. Proc Inst Mech Eng Part B J Eng Manuf 229(5):713-726. https://doi.org/10.1177/0954405414531114

8. Supekar SD, Clarens AF, Stephenson DA, Skerlos SJ (2012) Performance of supercritical carbon dioxide sprays as coolants and lubricants in representative metalworking operations. J Mater Process Technol 212(12):2652-2658. https://doi.org/10.1016/j. jmatprotec.2012.07.020

9. Ebbrell S, Woolley NH, Tridimas YD, Allanson DR, Rowe WB (2000) The effects of cutting fluid application methods on the grinding process. Int J Mach Tools Manuf 40(2):209-223. https://doi.org/ 10.1016/S0890-6955(99)00060-7

10. Schumack MR, Chung J-B, Schultz WW, Kannatey-Asibu E (1991) Analysis of fluid flow under a grinding wheel. J Eng Ind 113(2):190. https://doi.org/10.1115/1.2899677

11. Morgan MN, Jackson AR, Wu H, Baines-Jones V, Batako A, Rowe WB (2008) Optimisation of fluid application in grinding. CIRP Ann 57(1):363-366. https://doi.org/10.1016/j.cirp.2008.03.090
12. Madanchi N, Winter M, Thiede S, Herrmann C (2017) Energy efficient cutting fluid supply: the impact of nozzle design. Proc CIRP 61:564-569. https://doi.org/10.1016/j.procir.2016.11.192

13. Brinksmeier E, Heinzel C, Wittmann M (2007) Methoden zur Ermittlung einer bedarfsorientierten Kühlschmierstoffversorgung beim Schleifen. Jahrbuch Schleifen Honen Läppen Polieren 63:378-405

14. Washizu H, Ohmori $\mathrm{T}$ (2010) Molecular dynamics simulations of elastohydrodynamic lubrication oil film. Lubr Sci 22(8):323-340. https://doi.org/10.1002/ls.126

15. Al-Zoubi A, Brenner G (2008) Simulating fluid flow over sinusoidal surfaces using the lattice Boltzmann method. Comput Math Appl 55(7):1365-1376. https://doi.org/10.1016/j.camwa.2007. 08.013

16. Hryniewicz $P$, Szeri AZ, Jahanmir S (2001) Application of lubrication theory to fluid flow in grinding: part $\mathrm{i}$-flow between smooth surfaces. J Tribol 123(1):94. https://doi.org/10.1115/1. 1331277

17. Hryniewicz P, Szeri AZ, Jahanmir S (2001) Application of lubrication theory to fluid flow in grinding: Part II-influence of wheel and workpiece roughness. J Tribol 123(1):101. https://doi.org/ 10.1115/1.1331278

18. Müller M, Ostermeyer G-P, Bubser F (2013) A contribution to the modeling of tribological processes under starved lubrication. Tribol Int 64(135-147):2013. https://doi.org/10.1016/j.triboint. 2013.03.011

19. Müller M, Jäschke H, Bubser F, Ostermeyer G-PF (2014) Simulative studies of tribological interfaces with partially filled gaps. Tribology International 78:195-209. https://doi.org/10.1016/j. triboint.2014.05.002

20. Müller M, Völpel A, Ostermeyer G-P (2017) On the influence of fluid dynamics and elastic deformations on pressure buildup in partially filled gaps. Tribol Int 105:345-359. https://doi.org/10. 1016/j.triboint.2016.08.039

21. Müller M, Stahl L, Ostermeyer G-P (2018) Experimental studies of lubricant flow and friction in partially filled gaps. Lubricants 6(4):110. https://doi.org/10.3390/lubricants6040110

22. Ostermeyer G-P, Brumme S, Recke B (2017) The wear debris investigator-a new device for studying the formation of particles in the contact area. Eurobrake2017/EB2017-VDT-019, 2017.

23. Ostermeyer G-P, Rickhoff $F$ An experimental setup for investigations on the boundary layer dynamics. SAE Technical Paper 0148-7191.

Publisher's Note Springer Nature remains neutral with regard to jurisdictional claims in published maps and institutional affiliations. 